\title{
The first example of amine-induced reversal of diastereoselectivity in acylation of some trans-2-substituted cyclohexanols
}

\author{
Andrey V. Samoshin, Jasper Visser, Matthew Curtis, Vyacheslav V. Samoshin, and \\ Andreas H. Franz*
}

Department of Chemistry, University of the Pacific, 3601 Pacific Avenue, Stockton, CA 95211, $U S A^{\dagger}$

E-mail: afranz@pacific.edu

DOI: http://dx.doi.org/10.3998/ark.5550190.0013.803

\begin{abstract}
The reaction between racemic acyl chlorides and racemic trans-2-substituted-cyclohexanols proceeds diastereoselectively. We found for the first time that addition of a tertiary amine not only accelerates the acylation, but for some substituents leads to complete inversion of diastereoselectivity. These observations have been rationalized in terms of a possible stereoselective intramolecular assistance by the substituent group during the acylation of the neighboring hydroxyl group.
\end{abstract}

Keywords: Reversed stereoselectivity, double stereodifferentiation, stereoselective acylation, neighboring group participation

\section{Introduction}

The methods for kinetic resolution of racemates are based on a difference in reaction rates between enantiomers interacting with an asymmetric reagent or catalyst. Many examples have been described in the literature and the topic has been reviewed extensively. ${ }^{2-4}$ When both participating molecular species in a reaction are chiral, the result depends on the absolute configuration of each of them. This situation is described as 'double stereodifferentiation' or 'matched-mismatched' reaction partners. ${ }^{2-4}$ In particular, enantiopure acylating reagents allow for resolution of racemic alcohols and amines. ${ }^{2,3}$ The stereoselectivity of such reactions was found to depend on the structure of reactants, as well as on reaction conditions, e.g. solvent, temperature, and additives. ${ }^{2-11}$ Variation of conditions may cause a substantial change of stereoselectivity, sometimes even its reversal to an alternative configuration of a product. Such a reversal of enantioselectivity has been described for the transfer of non-chiral acyl groups from chiral reagents to racemic secondary amines (due to solvent and salt effects), ${ }^{5,6}$ and to racemic secondary alcohols ${ }^{7}$ and hemiaminals ${ }^{8}$ (due to the presence of strongly basic amines). Sensitivity to added amines has been found also for a diastereoselective transfer of chiral acyl groups to 
racemic substrates. Thus, a large change of the product diastereomeric excess caused by added amine was observed for the acylation of some racemic heterocyclic amines with optically active acyl chlorides. ${ }^{9}$ The excess varied from 14 to $80 \%$ depending on the additive, but the same diastereomer remained the major product. An even more dramatic change was reported for the kinetic resolution of racemic secondary alcohols by reaction with optically active acyl chlorides mediated by added $N$-methylimidazole: from $0 \%$ de in case of an acyl chloride itself to $98 \%$ de in presence of this amine. ${ }^{10}$ Interestingly, the reaction remained non-stereoselective in the presence of pyridine or DMAP. ${ }^{10}$ However, to the best of our knowledge, a reversal of diastereoselectivity during acylation as a result of solvent change or additive has never been observed before.

\section{Results and Discussion}

During the course of our studies towards synthetic applications of sulfonium ions, we found that for trans-2-(p-tolylsulfanyl)cyclohexanol 1a the extent of diastereoselectivity of acylation can be not only changed, but even reversed by addition of pyridine and other tertiary amines (Scheme 1). ${ }^{1}$ Herein we report results on the diastereoselectivity during acylation of structurally related trans-2-substituted cyclohexanols 1a-c with 2-chloropropanoyl chloride $\mathbf{2}$ as compared to trans2-methylcyclohexanol 1d. In our experiments, all reactants and the products of acylation were racemic mixtures.

The starting racemic trans-cyclohexanols 1a-c were prepared by cleavage of cyclohexene oxide (see Experimental Section). Racemic trans-2-methylcyclohexanol 1d was purchased and used without modifications. The acylation reactions were initially carried out with alcohol (1 mmol) and acyl chloride 2 (1.5 mol equiv.) in dichloromethane, in the presence or absence of pyridine additive (1-2 equiv.).

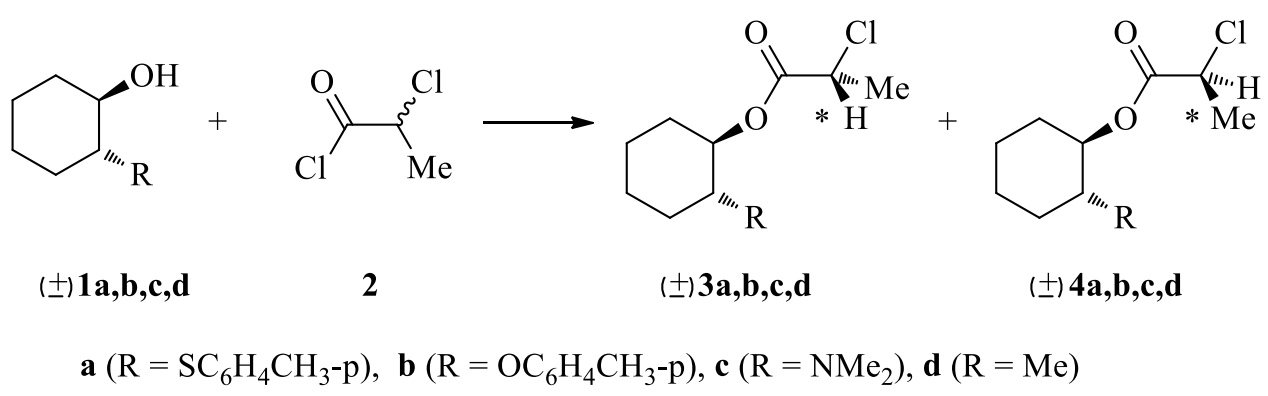

Scheme 1. Acylation of racemic trans-2-substituted cyclohexanols with racemic 2-chloropropanoyl chloride. The stereochemical assignments of $\mathbf{3}$ and $\mathbf{4}$ are arbitrary.

We also performed the acylation directly in NMR tubes in $\mathrm{CDCl}_{3}$ on a smaller scale and monitored the progress of reaction (Table 1). Two portions of $\mathbf{1}(0.1 \mathrm{mmol}$ or less each) were 
dissolved in $\mathrm{CDCl}_{3}$ along with equimolar amounts of the acid chloride 2. Pyridine- $d_{5}$ was added to one of these samples, and ${ }^{1} \mathrm{H}-\mathrm{NMR}$ spectra of the two samples were subsequently acquired periodically over $24 \mathrm{~h}$ to monitor the disappearance of $\mathbf{1}$ and the appearance of the ester products. The relative product ratios 3:4 remained constant in time throughout the experiment. Furthermore, the transient presence of one or multiple unidentified intermediate species was observed in the spectrum. The NMR-signals from the intermediate species increased in intensity initially and disappeared as the reactions progressed. Worthy of note was that the $24 \mathrm{~h}$ conversions for $\mathbf{1 b}$ (9\% without pyridine, $67 \%$ with pyridine) were significantly less than those of $1 \mathbf{a}$ and 1c derivatives (33-94\% without pyridine, $89 \%$ with pyridine) (Table 1). We also noticed that higher nucleophilicity of the substituent's heteroatom $X(O$ in $\mathbf{1 b} \rightarrow \mathrm{S}$ in $\mathbf{1 a} \rightarrow \mathrm{N}$ in 1c) or higher basicity of the reaction medium overall after addition of base caused higher reaction rates. This was consistent with the general behavior of acylation reactions. Interestingly, the use of $N, N$-diisopropylethylamine (Hünig's base) as a sterically-hindered additive slowed the reaction down.

Table 1. Data from ${ }^{1} \mathrm{H}-\mathrm{NMR}$ integration after $\sim 24 \mathrm{~h}( \pm 1 \mathrm{~h})$ in $\mathrm{CDCl}_{3}$ at $\mathrm{RT}$. Values are averages of triplicate experiments

\begin{tabular}{ccccc}
\hline Entry & Cpd. & ROH:RCOCl:Amine ${ }^{\mathrm{a}}$ & ${\text { Conversion, }{ }^{\mathrm{b}}}^{\mathrm{b}}$ & ${\text { Cpd. } 3: 4^{\mathrm{c}}}^{\mathrm{c}}$ \\
\hline 1 & $\mathbf{1 a}$ & $1: 1: 0$ & 33 & $1.0: 4.1$ \\
2 & $\mathbf{1 a}$ & $1: 2: 0$ & 56 & $1.0: 4.0$ \\
3 & $\mathbf{1 a}$ & $1: 1: 1$ & 89 & $3.2: 1.0$ \\
4 & $\mathbf{1 a}$ & $1: 2: 2$ & 100 & $2.5: 1.0$ \\
5 & $\mathbf{1 a}$ & $1: 2: 2^{\mathrm{d}}$ & 49 & $1.4: 1.0$ \\
6 & $\mathbf{1 b}$ & $1: 1: 0$ & 9 & $1.0: 4.2$ \\
7 & $\mathbf{1 b}$ & $1: 1: 1$ & 67 & $5.6: 1.0$ \\
8 & $\mathbf{1 c}$ & $1: 2.5: 0$ & 94 & $1.0: 2.7$ \\
9 & $\mathbf{1 c}$ & $1: 2.5: 2.5$ & $92^{\mathrm{e}}$ & $1.5: 1.0$ \\
10 & $\mathbf{1 d}$ & $1: 1: 0$ & 66 & $1.0: 1.5$ \\
11 & $\mathbf{1 d}$ & $1: 2: 0$ & 88 & $1.0: 1.4$ \\
12 & $\mathbf{1 d}$ & $1: 1: 1$ & 90 & $1.0: 1.3$ \\
13 & $\mathbf{1 d}$ & $1: 2: 2$ & 100 & $1.0: 1.2$ \\
\hline
\end{tabular}

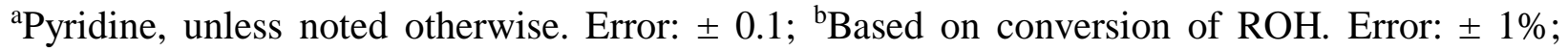
${ }^{\mathrm{c}}$ Arbitrary diastereomeric assignment. Error: \pm 0.1 ; ${ }^{\mathrm{d}}$ Hünig's base; ${ }^{\mathrm{e}}$ measured after only $1.3 \mathrm{~h}$ due to buildup of side products. 
The diastereomeric products of $\mathbf{3}$ and $\mathbf{4}$ were virtually inseparable by TLC or column chromatography. After chromatographic purification of the diastereomeric $\mathbf{3 / 4}$ mixtures, we determined the ratio from integral intensities of appropriate signals in ${ }^{1} \mathrm{H}-\mathrm{NMR}$ spectra (Figure 1). In all acylation experiments, we observed weak to modest diastereoselectivity (Table 1). The diastereoselectivities observed in triplicate experiments on the millimolar scale and on the NMRscale were comparable.
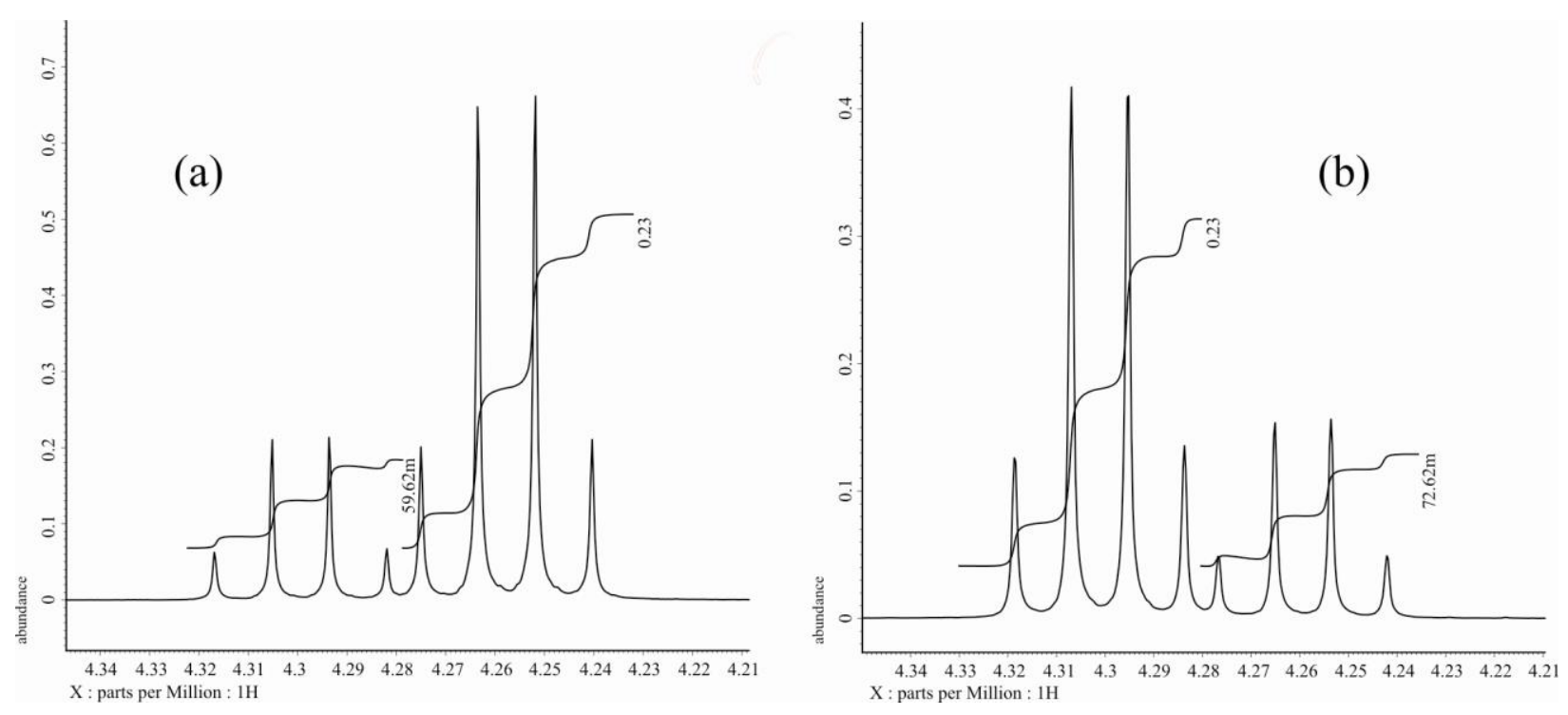

Figure 1. The signals $\mathrm{H}-* \mathrm{C}-\mathrm{Cl}$ in the ${ }^{1} \mathrm{H}-\mathrm{NMR}$ spectra $(600 \mathrm{MHz})$ of the isolated chloropropanoyl esters $\mathbf{3 a}$ and $\mathbf{4 a}$ of racemic trans-2-( $p$-tolylsulfanyl)cyclohexanol 1a, prepared in absence (a) and in presence (b) of pyridine.

The acylation of methylcyclohexanol 1d did not show much diastereoselectivity, and the addition of pyridine showed only a slight effect on the ratio of products $\mathbf{3 d}$ and $\mathbf{4 d}$ (arbitrary assignment of structures) within experimental error. However, in the case of hetero-substituted 1a-c, addition of pyridine led to an unprecedented reversal of diastereoselectivity (Table 1, Figure 1). In the case of sulfide 1a, the ratios of the isolated product mixtures in the macroscale reaction were 1:3.7 (average) without pyridine, and 2.7:1 (average) in the presence of pyridine. In the reactions on the NMR-scale, the respective ratios were 1:4 (average) and 2.8:1 (average). The small differences can likely be attributed to workup and chromatographic separation losses in the case of experiments on larger scale. Very similar reversal of diastereoselectivity upon addition of pyridine was also seen in the ether and amine derivatives $\mathbf{1 b}$ and $\mathbf{1 c}$, respectively. The strongest reversal of product distributions was observed in the case of ether $\mathbf{1 b}$. The diastereomeric ratio of the ester products $\mathbf{3 b}: \mathbf{4} \mathbf{b}$ changed from 1:4.2 in the absence of pyridine to 5.6:1 when pyridine was present. These data point to the central role the substituent's heteroatom plays in the diastereoselectivity of reaction. 
The possibility of isomerization or stereochemical scrambling due to the presence of pyridine over time was ruled out. The purified product mixtures obtained from reactions in absence or presence of pyridine were mixed subsequently with pyridine- $d_{5}$ and allowed to stay at room temperature for over a week with no discernible effects on the distributions of the diastereomers in either of the two mixtures.

The observed reversal of diastereoselectivity may result from a change in relative contributions by the alternative competitive acyl transfer pathways with different diastereoselectivities (Scheme 2). Amines are known to react quickly with acid anhydrides and acyl chlorides to produce even more active acylating agents - acyl ammonium salts; thus, they act as catalysts. For instance, pyridine and its derivatives are very popular catalysts for acylation. ${ }^{12,13}$ Different shape, size and positive charge of acyl pyridinium compared to acyl chloride may provide the simplest explanation for the change of stereoselectivity. However, the previously published data ${ }^{5-10}$ did not reveal such a dramatic role of pyridine in similar reactions. We suggest that the participation of $\mathrm{RX}$ as a neighboring group in the absence of more basic/nucleophilic species like pyridine is a reasonable mechanistic explanation for the amineinduced reversal of diastereoselectivity.

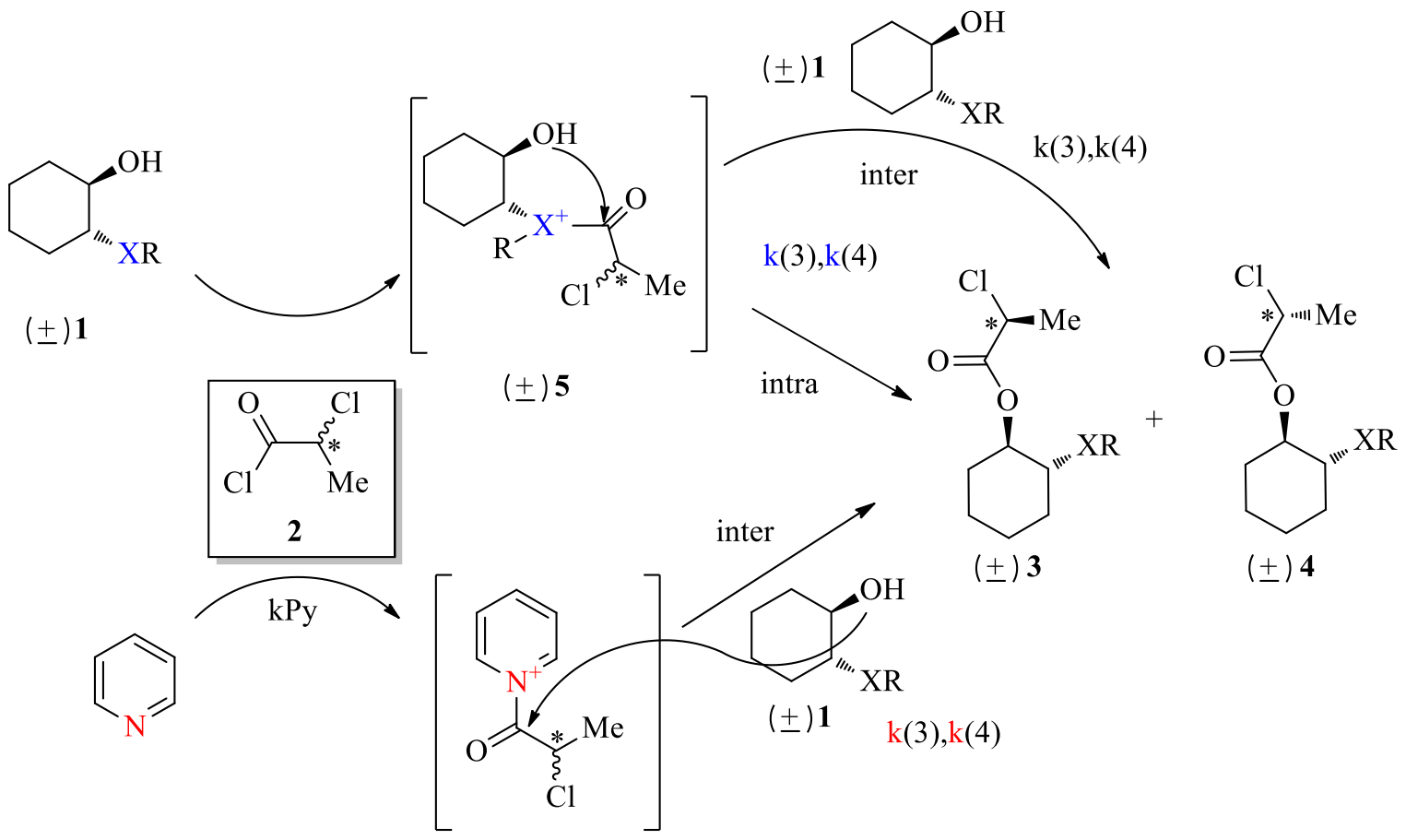

Scheme 2. Plausible pathways leading to the observed amine-induced reversal of diastereoselectivity in the acylation of alcohols $\mathbf{1}$.

When no amine is added, the preliminary complexation/coordination of the acyl chloride with the nucleophilic atom $X$ produces an intermediate acylium ion $\mathbf{5}$ from which the acyl group is transferred intramolecularly to the neighboring hydroxyl group (Scheme 2). The two intermediate acylium diastereomers can be assumed to form with different rates and transfer the 
acyl group intramolecularly with different rates. Overall, the diastereomers 3a and 4a result in different amounts reflecting differences in rate of formation.

In presence of pyridine the reaction takes a different pathway. Pyridine forms the acyl pyridinium cation quickly and predominantly for subsequent intermolecular transfer of the acyl moiety to the alcohol group. The transition state and resulting diastereoselectivity for this process will be markedly different from the intramolecular mechanism described above. It will be different from other mechanistic alternatives as well: direct acylation of the hydroxyl by $\mathbf{2}$ or intermolecular acyl transfer from $\mathbf{5}$ to another molecule of $\mathbf{1}$. However, the latter are likely only minor contributing pathways as the hydroxyl is not a particularly good nucleophile, and the intermolecular acyl transfer from $\mathbf{5}$ to another molecule of $\mathbf{1}$ would probably require substantial structural reorganization and be kinetically slower than an intramolecular transfer within $\mathbf{5}$.

The variation of diastereoselectivity of acylation with the nature of group RX seems to support the concept of the intramolecular acyl transfer. Thus, ether $\mathbf{1 b}$ with weakly basic oxygen demonstrated the most significant reversal of diastereoselectivity, while the stronger basicity of the tertiary amine in 1c led to the smallest diastereoselectivity. This is reasonable as oxygen is neither very basic nor nucleophilic, and thus cannot compete for the acyl group with the much more nucleophilic and, thus more reactive pyridine. The more basic and nucleophilic nitrogen of the dimethylamino moiety in 1c competes favorably with the less sterically-hindered but less nucleophilic pyridine, thus leading to the reduced effect of the latter on diastereoselectivity. Compared to oxygen and nitrogen, the sulfur in sulfide 1a has intermediate nucleophilicity and its acylation showed diastereoselectivity effects between those for $\mathbf{1 b}$ and $\mathbf{1 c}$.

\section{Conclusions}

To the best of our knowledge, we have observed the first example of acylation of certain racemic trans-2-substituted cyclohexanols with racemic acyl chloride during which the addition of a tertiary amine led to the reversal of diastereoselectivity. Further studies of this and other reactions are in progress including variation of the nucleophilic additives and the structure of alcohols and acylating agents.

\section{Experimental Section}

General. Cyclohexene, $p$-thiocresol, $p$-cresol, dimethylamine (solution), NBS, and pyridine were obtained from Sigma-Aldrich. The compounds trans-2-methylcyclohexanol (1d) and 2chloropropanoyl chloride (2) were purchased from Alfa Aesar. Column chromatography was performed on silica gel (Sorbent Technologies, 40-75 $\mu \mathrm{m}$ ). ${ }^{1} \mathrm{H}-\mathrm{NMR}$ and ${ }^{13} \mathrm{C}-\mathrm{NMR}$ spectra were acquired on a JEOL ECA-600 NMR-spectrometer (600 and $150 \mathrm{MHz}$, respectively). Accurate mass measurements were performed on the JEOL AccuTOF DART Mass Spectrometer 
(Peabody, MA, USA) with a resolving power of 7,500 with polyethyleneglycol as an internal reference.

Compound ( \pm )1a $[( \pm)$-trans-2-(p-tolylsulfanyl)cyclohexanol $] .{ }^{14}$ To a solution of cyclohexene (10.2 mL, $100 \mathrm{mmol})$ in aqueous THF (200 mL, THF/ $\left.\mathrm{H}_{2} \mathrm{O} 3: 1\right)$, NBS (21.44 g, $\left.120 \mathrm{mmol}\right)$ was added slowly and left to stir overnight. Diethyl ether $(200 \mathrm{~mL})$ was added to the reaction mixture followed by $\mathrm{NaOH}$ solution $(10 \%, 100 \mathrm{~mL})$ and left to stir overnight. The aqueous layer was separated from the organic and extracted with diethyl ether $(75 \mathrm{~mL})$. Organic phases were combined and dried $\left(\mathrm{Na}_{2} \mathrm{SO}_{4}\right)$. Organic layer was decanted from the drying agent and concentrated by distillation to $55 \mathrm{~mL}$. This solution of cyclohexene epoxide was then used to dissolve $p$-thiocresol (13.64 g, $110 \mathrm{mmol}$ ) followed by the addition of borax (anhydrous, $2.07 \mathrm{~g}$ $10.0 \mathrm{mmol}$ ) and water $(50 \mathrm{~mL})$. The reaction mixture was set to stir at $50{ }^{\circ} \mathrm{C}$ (controlled by water bath) for $2 \mathrm{~h}$. THF was removed by distillation and remaining aqueous solution was mixed with $\mathrm{NaOH}$ solution $(5 \%, 150 \mathrm{~mL})$ and stirred for $30 \mathrm{~min}$. The aqueous solution was extracted with $\mathrm{CH}_{2} \mathrm{Cl}_{2}(3 \times 100 \mathrm{~mL})$. The extracts were combined and dried $\left(\mathrm{Na}_{2} \mathrm{SO}_{4}\right)$. Filtration and evaporation of the solution yielded a yellow viscous liquid $(22.11 \mathrm{~g})$ that was column chromatographed (silica gel, $\mathrm{CH}_{2} \mathrm{Cl}_{2}$ ) to afford the product as clear oil. Yield: $18.12 \mathrm{~g}$ of $(81.6 \%$ yield). ${ }^{1} \mathrm{H}$ NMR (600 MHz, $\left.\mathrm{CDCl}_{3}\right): \delta_{\mathrm{H}} 1.26\left(\mathrm{~m}, 4 \mathrm{H}, \mathrm{CH}_{2}\right), 1.66\left(\mathrm{~m}, \mathrm{CH}_{2}\right), 2.07\left(\mathrm{~m}, \mathrm{CH}_{2}\right), 2.32$ (s, $\left.\mathrm{CH}_{3}\right), 2.66(\mathrm{~m}, \mathrm{H} 2), 3.27$ (dt, H1), 7.10, $7.35(\mathrm{Ph}),{ }^{13} \mathrm{C} \mathrm{NMR}\left(150 \mathrm{MHz}, \mathrm{CDCl}_{3}\right): \delta_{\mathrm{C}} 138.13$, 134.59, 129.65, 128.23 (C, CH, S-tolyl), 71.74 (C1), 56.62 (C2), 33.70 (C6), 32.49 (C3), 26.16 (C5), 24.26 (C4), $21.09\left(\mathrm{PhCH}_{3}\right) . \mathrm{MS} \mathrm{m} / z$ (rel. intensity): 205.1054 (100), 222.1069 (19) [M ${ }^{++}$, $223.1153(7.7)[\mathrm{M}+\mathrm{H}]^{+}$. HRMS: $m / z$ calcd for $\mathrm{C}_{13} \mathrm{H}_{18} \mathrm{OS}\left[\mathrm{M}^{+}\right] 222.1078$, found 222.1070 .

Compound ( \pm )1b [( \pm )-trans-2-(p-tolyloxy)cyclohexanol]. $p$-Cresol (516 mg $4.8 \mathrm{mmol})$ was dissolved in cyclohexene oxide $(450 \mathrm{mg}, 4.6 \mathrm{mmol})$ and a catalytic amount sulfuric acid was added and left to stir overnight at rt. The reaction mixture was separated by column chromatography (alumina, $\mathrm{CH}_{2} \mathrm{Cl}_{2}$ ) to afford a white wax-like solid. Yield: $106 \mathrm{mg}(11 \%) .{ }^{1} \mathrm{H}$ NMR (600 MHz, $\left.\mathrm{CDCl}_{3}\right): \delta_{\mathrm{H}} 1.33\left(\mathrm{~m}, 4 \mathrm{H}, \mathrm{CH}_{2}\right), 1.74\left(\mathrm{~m}, \mathrm{CH}_{2}\right), 2.11\left(\mathrm{~m}, \mathrm{CH}_{2}\right), 2.29\left(\mathrm{~s}, \mathrm{CH}_{3}\right)$, $3.70(\mathrm{~m}, \mathrm{H} 2), 3.93(\mathrm{~m}, \mathrm{H} 1), 6.85,7.08(\mathrm{Ph}) .{ }^{13} \mathrm{C} \mathrm{NMR}\left(150 \mathrm{MHz}, \mathrm{CDCl}_{3}\right): \delta_{\mathrm{C}} 155.61,130.66$, 129.98, 116.46 (C, CH, O-tolyl), 82.55 (C1), 73.51 (C2), 31.99 (C6), 29.20 (C3), 24.00 (C5), 23.92 (C4), $20.49\left(\mathrm{PhCH}_{3}\right) . \mathrm{MS} \mathrm{m} / z$ (rel. intensity): 189.1289 (100), 207.1370 (67) $[\mathrm{M}+\mathrm{H}]^{+}$, $224.1635(72)\left[\mathrm{M}+\mathrm{NH}_{4}\right]^{+}$. HRMS: $m / z$ calcd for $\mathrm{C}_{13} \mathrm{H}_{19} \mathrm{O}_{2}[\mathrm{M}+\mathrm{H}]^{+} 207.1385$, found 207.1370.

Compound $( \pm) 1 \mathrm{c}[( \pm)$ trans-2-(dimethylamino)cyclohexanol]. Cyclohexene oxide (1.476 g, 15 mmol) was mixed with $40 \%$ by weight aqueous solution of dimethylamine $(20.0 \mathrm{~mL}, 158$ mmol), followed by the addition of THF until the mixture was homogenized. Solution was flushed with nitrogen and allowed to react at room temperature overnight. The reaction mixture was evaporated in vacuo and separated by column chromatography: alumina, ethyl acetate/hexane 1:1. Separation yielded product as waxy whitish crystals. Yield: $1.31 \mathrm{~g}(61 \%$ yield). ${ }^{1} \mathrm{H}$ NMR (600 MHz, $\left.\mathrm{CDCl}_{3}\right): \delta_{\mathrm{H}} 3.51$ (dt, H1), $2.86(\mathrm{~m}, \mathrm{H} 2), 2.63(\mathrm{~s}, 6 \mathrm{H}), 2.12(\mathrm{~m}, 2 \mathrm{H})$, 1.92, 1.83, $1.74(\mathrm{~m}, 3 \mathrm{H}), 1.37(\mathrm{~m}, 1 \mathrm{H}), 1.24(\mathrm{~m}, 3 \mathrm{H}) .{ }^{13} \mathrm{C} \mathrm{NMR}\left(150 \mathrm{MHz}, \mathrm{CDCl}_{3}\right): \delta_{\mathrm{C}} 70.01$ (C2), 68.82 (C1), $39.30\left(\mathrm{CH}_{3}\right), 34.55\left(\mathrm{CH}_{3}\right), 24.55$ (C3), 24.17 (C6), 22.72 (C4), 22.6 (C5). MS 
$m / z$ (rel. intensity): 144.1374 (100), HRMS: $m / z$ calcd for $\mathrm{C}_{8} \mathrm{H}_{18} \mathrm{NO},[\mathrm{M}+\mathrm{H}]^{+} 144.1388$, found 144.1374 .

\section{Acylation of ( \pm )-trans-2-substituted-cyclohexanols (1). General procedure}

( \pm )-trans-2-Substituted cyclohexanol $(0.5 \mathrm{mmol})$ was dissolved in $\mathrm{CH}_{2} \mathrm{Cl}_{2}(3 \mathrm{~mL})$. In reactions done with amines, the amine (e.g. pyridine) was added at this point in the desired quantity. The acyl chloride was added via graduated capillary. The reaction mixture was monitored by TLC and allowed to stir until no starting alcohol was left. The reaction mixture was evaporated and separated by column chromatography packed with silica. The products were all isolated as colorless oils.

Compounds $\quad( \pm)-(3 a+4 a) \quad[( \pm)$-trans-2-(p-tolylsulfanyl)cyclohexyl 2-chloropropanoate $]$. According to the general procedure 1 (eluent toluene) a mixture of diastereomers was obtained. Yield: $77 \%$ without pyridine and $64 \%$ with pyridine. ${ }^{1} \mathrm{H} \mathrm{NMR}\left(600 \mathrm{MHz}, \mathrm{CDCl}_{3}\right): \delta_{\mathrm{H}} 1.40(\mathrm{~m}$, $\left.4 \mathrm{H}, \mathrm{CH}_{2}\right), 1.66\left(\mathrm{~d}, 3 \mathrm{H}, \mathrm{COCH}_{3}\right), 1.68\left(\mathrm{~d}, 3 \mathrm{H}, \mathrm{COCH}_{3}\right), 1.70(\mathrm{~m}, 2 \mathrm{H}), 2.09(\mathrm{~m}, 2 \mathrm{H}), 2.33(\mathrm{~s}, \mathrm{H} 3$, $\mathrm{PhCH}_{3}$ ), 3.10 (dt, H2), 4.26 (q, COCHCl), 4.30 (q, COCHCl), 4.79 (dt, H1), 7.11 (m, 2H, S-Tol), $7.34(\mathrm{~m}, 2 \mathrm{H}, \mathrm{S}-\mathrm{Tol}) .{ }^{13} \mathrm{C} \mathrm{NMR}\left(150 \mathrm{MHz}, \mathrm{CDCl}_{3}\right): \delta_{\mathrm{C}} 169.28(\mathrm{C}=\mathrm{O}), 137.58,133.48,129.89$, 129.63 (C, CH, S-tolyl), 76.19 (C1), 52.98 (COÇHClMe), 50.06 (C2), 31.32 (C6), 30.51 (C3), 24.57 (C5), 23.18 (C4), 21.60, $21.08\left(\mathrm{CHClCH}_{3}\right) . \mathrm{MS} \mathrm{m} / \mathrm{z}$ (rel. intensity): 205.1032 (100), 312.0954 (3.9) $\left[\mathrm{M}^{+\cdot}\right], 330.1283$ (7.7) $\left[\mathrm{M}+\mathrm{NH}_{4}\right]^{+}$. HRMS: $m / z$ calcd for $\mathrm{C}_{16} \mathrm{H}_{21} \mathrm{ClO}_{2} \mathrm{~S}\left[\mathrm{M}^{+}\right]$ 312.0951, found 312.0954.

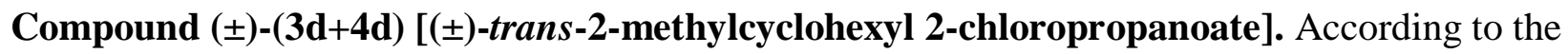
general procedure 1 (eluent toluene) a mixture of diastereomers was obtained. Yield: $83 \%$ without pyridine and $73 \%$ with pyridine. ${ }^{1} \mathrm{H} \mathrm{NMR}\left(600 \mathrm{MHz}, \mathrm{CDCl}_{3}\right): \delta_{\mathrm{H}} 0.91\left(\mathrm{~d}, \mathrm{CH}_{3}\right), 0.93(\mathrm{~d}$, $\left.\mathrm{CH}_{3}\right), 1.22$ (m, H3), 1.24 (m, H4), 1.32 (m, H6), 1.63 (m, H2), 1.63 (m, H4), 1.63 (t, $\mathrm{COCHClC}_{3}$ ), 1.78 (m, 2H, H5), 1.98 (m, H6) 4.38 (q, COC $\underline{\mathrm{HCl}}$ ), 4.47 (dt, H1), ${ }^{13} \mathrm{C}$ NMR (150 $\mathrm{MHz}, \mathrm{CDCl}_{3}$ ): $\delta_{\mathrm{C}} 169.76(\mathrm{C}=\mathrm{O}), 80.24(\mathrm{C} 1), 52.98$ (COCLHClMe), 37.15 (C2), 33.39 (C6), 31.32 (C3), 25.17 (C5), $24.59(\mathrm{C} 4), 21.5\left(\mathrm{CHClCH}_{3}\right) 18.25\left(\mathrm{CH}_{3}\right) . \mathrm{MS} \mathrm{m} / z$ (rel. intensity): 97.1014 (89.9), 205.0977 (49) $[\mathrm{M}+\mathrm{H}]^{+}, 207.0970$ (13.7), 222.1240 (100) [M+NH$]^{+}, 224.1225$ (30.8). HRMS: $m / z$ calcd for $\mathrm{C}_{10} \mathrm{H}_{18} \mathrm{ClO}_{2}[\mathrm{M}+\mathrm{H}]^{+} 205.0995$, found 205.0977.

\section{Acylation of ( \pm )-trans-2-substituted-cyclohexanols (NMR scale) (2). General procedure}

$( \pm)$-trans-2-Substituted cyclohexanol $(0.1 \mathrm{mmol})$ was dissolved in $\mathrm{CDCl}_{3}(\sim 0.7 \mathrm{~mL})$ in a glass vial, followed by the addition of amine (in reactions involving amines). This was followed by the addition of the acyl chloride, and immediate mixing and transfer to an NMR tube. NMR spectra were recorded right after mixing and at intervals over the following $48 \mathrm{~h}$.

Compound $\quad( \pm)(3 \mathrm{~b}+4 \mathrm{~b}) \quad[( \pm)$-trans-2-(tolyloxy)cyclohexyl 2-chloropropanoate]. Only synthesized according to general procedure 2 and analyzed in situ in NMR scale experiments.

Compound $( \pm)(3 c+4 c)[( \pm)$-trans-2-(dimethylamino)cyclohexyl 2-chloropropanoate]. Only synthesized according to general procedure 2 and analyzed in situ in NMR scale experiments. 


\section{Acknowledgements}

The National Science Foundation Major Research Instrumentation Grant (CHE-0722654) is gratefully acknowledged for the funding of a JEOL ECA-600 NMR-spectrometer.

\section{References}

${ }^{\dagger}$ Part of this material was presented as a poster at the American Chemical Society $22^{\text {nd }}$ Annual Northern California Undergraduate Research Symposium in Sacramento State University, CA (May 2010) and the $242^{\text {nd }}$ National Meeting of the ACS in Anaheim, CA (March 2011). ${ }^{1}$

1. Samoshin, A.; Visser, J.; Curtis, M.; Franz, A. H. $241^{\text {st }}$ ACS National Meeting \& Exposition, Anaheim, CA, United States, March 27-31, 2011: Abstract No. p ORGN-761.

2. Eliel, E. L.; Wilen, S. H.; Mander, L. N. Stereochemistry of Organic Compounds, 1994.

3. Somfai, P. Angew. Chem., Int. Ed. 1998, 36, 2731-2733.

4. Masamune, S.; Choy, W.; Petersen, J. S.; Sita, L. R. Angew. Chem. 1985, 97, 1-31.

5. Arseniyadis, S.; Valleix, A.; Wagner, A.; Mioskowski, C. Angew. Chem., Int. Ed. 2004, 43, 33143317.

6. Arseniyadis, S.; Subhash, P. V.; Valleix, A.; Mathew, S. P.; Blackmond, D. G.; Wagner, A.; Mioskowski, C. J. Am. Chem. Soc. 2005, 127, 6138-6139.

7. Kashima, C.; Mizuhara, S.; Miwa, Y.; Yokoyama, Y. Tetrahedron: Asymmetry 2002, 13, 1713-1719.

8. Yamada, S.; Noguchi, E. Tetrahedron Lett. 2001, 42, 3621-3624.

9. Krasnov, V. P.; Levit, G. L.; Korolyova, M. A.; Bukrina, I. M.; Sadretdinova, L. S.; Andreeva, I. N.; Charushin, V. N.; Chupakhin, O. N. Russ. Chem. Bull. 2004, 53, 1253-1256.

10. Leclercq, L.; Suisse, I.; Agbossou-Niedercorn, F. Eur. J. Org. Chem. 2010, 2696-2700.

11. Cainelli, G.; Galletti, P.; Giacomini, D.; Gualandi, A.; Quintavalla, A. Helv. Chim. Acta 2003, 86, 3548-3559.

12. Fieser, M.; Fieser, L. F. Reagents for Organic Synthesis, Wiley-Interscience: New York, 1972; Vol. 3.

13. Berry, D. J.; DiGiovanna, C. V.; Metrick, S. S.; Murugan, R. Arkivoc 2001, (ii), 201-226.

14. Gao, P.; Xu, P.-F.; Zhai, H. Tetrahedron Lett. 2008, 49, 6536-6538. 